\title{
La dialéctica entre el pensar y el sentir: el uso comunicativo de las nuevas capacidades tecnológicas
}

\section{Dialectic between thinking and feeling: the communicative use of the new technological capacities}

\author{
Claudio Pereira Salazar ${ }^{1}$ \\ Universidad Santo Tomás, Chile
}

(Recepción: Agosto 2007 - Aceptación: Enero 2008)

\begin{abstract}
Resumen
El pensamiento dialéctico y su influencia en el reciente paradigma de la complejidad nos permite realizar una lectura del fenómeno psicológico y comunicativo que emerge de la dialéctica entre el pensar y el sentir del ser humano en interacción con las nuevas capacidades tecnológicas. Se organiza la exposición en cuatro momentos, en primer lugar, se desarrolla lo que caracteriza al pensamiento dialéctico y sus implicancias en la emergencia de un nuevo paradigma y, una vez aclarado este ámbito, nos aproximaremos a una dialéctica entre el pensar y el sentir en la experiencia y conciencia del individuo. En este punto veremos las relaciones posibles de interacción con las nuevas capacidades tecnológicas, en particular con el hipertexto y sus consecuencias sociocognitivas. Posteriormente se centra el análisis en la reflexión sobre los alcances de la cibercultura, para finalizar con una visión de los usos comunicativos en el ámbito de la educación y el desarrollo.

Palabras claves: Conciencia, Cibercultura, Complejidad.
\end{abstract}

\begin{abstract}
The dialectic thought and its influence in the recent paradigm of the complexity allows us to make a reading of the psychological and communicative phenomenon that emerges from the dialectic one between thinking and feeling of the human being in interaction with the new technological capacities. The exhibition is organized in four steps. First, it is developed what characterizes the dialectic thought and its problems in the origin of a new paradigm and, once clarified this scope we will be close to a dialectic between thinking and feeling about the experience and conscience of the individual. In this stage we will have the possible relations of interaction with the new technological capacities, in particular with the hypertext and its social and cognitive consequences. Later the analysis is centered on the reaches of the cibercultura, to finish with a vision of the communicative uses in the scope of the education and the development.
\end{abstract}

Key words: Conscience, Cyberculture, Complexity

\section{La Dialéctica}

¿Dialéctica entre el pensar y el sentir?

En la búsqueda de una respuesta a esta interrogante surge la necesidad primera de aclarar qué es la dialéctica ya que se trata de una forma de pensamiento de profundas consecuencias en la comprensión de los fenómenos de la comunicación y de conciencia. El método dialéctico fue desarrollado científicamente como un medio de comprender el desarrollo de la sociedad humana, por Marx y Engels, pero antes que ellos ya tenía una larga existencia.

1 Correspondencia a: Claudio Pereira Salazar. Dirección Postal: Sucre 363, dpto. 44. Antofagasta, Chile. Teléfonos: (55) 416326 / 09-9058658 E-mail: cpereira@santotomas.cl 
Los griegos antiguos produjeron algunos grandes pensadores dialécticos, entre los que están Platón, Zenón de Elea y Aristóteles. Ya en el año 500 antes de nuestra era, Heráclito adelantaba la idea de que "todas las cosas son y no son, porque todo fluye, está cambiando constantemente, naciendo y muriendo. Una metáfora apropiada es que "es imposible sumergirse dos veces en uno e idéntico río”. Hasta aquí se tiene una primera aproximación al sentido originario de la visión dialéctica, pero profundicemos un poco más en su desarrollo.

El hombre piensa y acciona, pero también siente. Miedos, angustias, ambiciones, amor, odio, dolor; contradicciones y conflictos son recogidos por los mitos y las ideologías y comprometen la experiencia humana. Esta forma de ver la realidad, partiendo de la realidad misma, de su forma de ser múltiple, compleja, contradictoria y en permanente cambio, va a fundar la concepción dialéctica. La palabra será inventada por Platón, pero antes fue desarrollada por Heráclito (Lee, 2007).

Pero en este período también aparece un personaje cuyo pensamiento será influyente en el desarrollo de la ciencia, Parménides, quien descubre lo que será el principio lógico de identidad. Llega a la conclusión de que hay dos mundos: Un mundo sensible lleno de variedad y movimiento, de cosas que van y vienen, nacen y mueren, lleno de olores sabores, colores, lleno de contradicciones absurdas e incomprensibles para la razón. Este mundo es una mera apariencia porque la percepción sensible es una ilusión que no nos permite comprender lo auténtico. Por otro lado, tenemos un mundo inteligible, al que no vemos ni tocamos pero está sometido a la lógica de la identidad y nocontradicción y podemos comprender a través del pensamiento, de la razón. Sostiene Parménides que para descubrir qué es lo que es en realidad, no tenemos más guía que el principio de identidad, y con ello asienta la tesis fundamental de que las cosas fuera de mí, el ser fuera de mí, es exactamente idéntico a mi pensamiento del ser. Dice Parménides "Una y la misma cosa es ser y pensar” (citado en Lee, 2007, p. 1).

Queda planteada así una concepción, que buscará el conocimiento de las esencias ocultas de las cosas más allá de las apariencias y las experiencias e impondrá una noción estática, no dinámica de la realidad, sujeta al principio formal de identidad que fundará el pensamiento lógico de Occidente, impondrá a la razón por veinticinco siglos como única vía de conocimiento.

Así, en base a estos planteamientos, se desarrolló la historia de la ciencia y del pensamiento occidental, hasta que desde la filosofía retoma los pensamientos de la antigüedad Hegel. A diferencia de sus antecesores que sostenían la necesidad de separar la realidad en partes, intuitivamente Hegel afirmó que "Todo se relaciona con todo". "Cada pieza cobra sentido cuando se la ve como parte de todo el rompecabezas. Cada cosa es una unidad de contrarios, en el sentido de que cada cosa está compuesta de elementos que, hallándose inseparablemente vinculados entre sí, se excluyen al mismo tiempo" (citado en Lee, 2007, p. 1).

Posteriormente Engels define la dialéctica como la ciencia de las leyes generales del movimiento y la evolución de la naturaleza, la sociedad humana y el pensamiento. Naturaleza, sociedad y pensamiento se desarrollan dialécticamente (Lee, 2007).

La dialéctica, además de un método de pensamiento, es una forma de interpretación esencialmente dinámica de los fenómenos y procesos de la materia a nivel orgánico e inorgánico. Es la expresión de una nueva realidad que trasciende por completo los postulados de la lógica clásica y nuestro lenguaje corriente.

Para la dialéctica no existe la naturaleza más el movimiento, ni la sociedad más el movimiento. La realidad es movimiento, cambio y transformación. Dice Engels: "El movimiento, en su sentido más general, concebido como modo de existencia, atributo inherente a la materia, abarca todos los cambios y procesos que se producen en el universo, desde el simple cambio de lugar hasta el pensamiento. La investigación de la naturaleza del movimiento debe comenzar por las formas inferiores, más simples y aprender a entenderlas antes de llegar a una explicación de las formas más elevadas y complicadas” (citado en Lee, 2007, p. 1). 
Veamos ahora cómo opera el pensamiento dialéctico para luego aproximarnos a la dialéctica enre el pensar y el sentir, en tanto proceso que establece una relación con el uso comunicativo de las nuevas capacidades tecnológicas.

Engels formula las principales leyes de la dialéctica: Ley del movimiento, Ley del cambio y ley del desarrollo y la evolución.

1 - Ley del movimiento dialéctico. La contradicción

Mientras que la lógica formal intenta desterrar el movimiento, éste es la esencia de la dialéctica. Lo que produce el movimiento es la contradicción.

La contradicción es ese factor constante de antagonismo que permite a los constituyentes del sistema aproximarse y separarse, asociarse y disociarse, integrarse y desintegrarse; esa fuerza que, en la perpetua danza de creación y destrucción del universo, da forma a los constantes flujos de energía.

La realidad última como unidad de opuestos -materia y actividad, forma y contenido- es contradictoria, y el movimiento, que en sí mismo implica una contradicción, solo es posible como resultado de tendencias en conflictos, tensiones internas que residen en el corazón de todas las formas de materia.

Las cosas son una unidad de contrarios. Cada cosa es ella misma y su contrario, porque en su interior existen fuerzas antagónicas que luchan en direcciones contrarias.

Pero la contradicción implica identidad y lucha de contrarios. Los opuestos no son meramente diferentes sino opuestos, es decir, idénticos en todo excepto en que unos son positivos y otros negativos, no importa cuál. Lo que importa es la relación entre esos opuestos: los iguales se repelen y los contrarios se atraen. La unión o separación solo existe en la conexión entre ambos.

La exclusión de uno de los polos detiene el crecimiento. En cambio la integración de los opuestos en la síntesis, transforma lo dilemático en problemático, integra lo fragmentado, permite el cambio y el crecimiento y resuelve el conflicto. Pero el equilibrio abrirá nuevas contradicciones y conflictos a resolver.

\section{2 - Ley del cambio dialéctico. De la cantidad a la calidad y viceversa}

Los procesos de cambio demandan tiempo y determinadas condiciones. Pero en un momento determinado, la línea lenta de cambios cuantitativos acumulados sufre una rápida aceleración y en un salto repentino, alcanza el estado de transición, el punto crítico en el que la materia cambia de estado, la cantidad se transforma en una nueva cualidad, un estado distinto con nuevas propiedades, en el que los componentes del todo se reorganizan en un modelo diferente.

También la conciencia se desarrolla mediante saltos bruscos. El punto crítico en que los pequeños cambios de grado dan lugar a cambios de estado (Ej. sólido a líquido, líquido a vapor), se conoce como transición de fase, que no es otra cosa que un salto cualitativo. Esto es uno de los problemas fundamentales de la ciencia y una cuestión que ocupa un lugar central en el materialismo dialéctico.

Lo que determina las cualidades y propiedades de las cosas es la interacción, o acción mutua de los contrarios y en consecuencia para comprenderlas no alcanza el análisis formal reducido a sus componentes individuales. Es necesario un análisis dialéctico que permita entender las interrelaciones dinámicas de esos componentes.

3.- Ley del desarrollo y la evolución. Negación de la negación

La tercera ley expresa la idea del desarrollo o evolución espiralada.

La negación dialéctica significa la destrucción pero también preservación, como expresión del auto-dinamismo interno de los seres, cosas y hechos que permite la emergencia de lo nuevo desde lo viejo. 
Hegel da un ejemplo muy simple en su libro Fenomenológica de la mente: El capullo (de una flor) desaparece cuando los pétalos florecen y podríamos decir que la forma original es negada por la posterior; en el mismo sentido, cuando surge la fruta, la flor (pétalos, estambres...) puede ser explicada como una falsa forma de la existencia de la planta para que la fruta aparezca como su propia naturaleza en lugar de la flor. No hay en estos procesos un mero cambio sino una real transformación y desarrollo.

Lo mismo sucede con la discusión dialéctica, que bajo el enfoque de los nuevos paradigmas Edgar Morín llama dialógica: Se plantea una idea o tesis y se la contrapone al punto de vista contrario o antítesis. Esta negación o antítesis marca un avance definido y de hecho, un salto cualitativo. Cada avance niega el estadio anterior, reacciona en su contra, pero al mismo tiempo preserva todo lo que de útil y necesario hay en él. A través del proceso del diálogo que explora el asunto desde todos los puntos de vista, se descubren las contradicciones ocultas y se llega a una conclusión o Síntesis.

La dialéctica considera los procesos fundamentales del universo, la sociedad y la historia de las ideas como una espiral abierta de desarrollo, en la que nada se repite nunca de la misma manera, cada punto crece y se desarrolla porque en cada pasaje se eleva a un plano superior.

La dialéctica es una ciencia y una lógica del cambio y del movimiento. Ella no fue creada o fabricada por los antiguos chinos o filósofos hindúes o aun por Hegel y Marx, sino que fue descubierta por todos ellos, y cada pensador dialéctico está haciendo una contribución científica para entender las leyes de la sociedad, de la historia y del universo, las cuales, en sí mismas, están sujetas a cambio, a dialéctica.

Podemos aventurarnos a partir de esta línea de pensamiento en los trabajos de Edgar Morin para quien la intuición de Hegel es hoy confirmada por la teoría de la complejidad: la realidad es un entramado tenido en conjunto en el que el todo es más que la suma de las partes pero se manifiesta en cada parte.

La dialéctica entonces, compleja por esencia, se integra sin esfuerzo con las concepciones de la complejidad y por eso se habla ahora de dialéctica compleja. Se integra perfectamente con las recientes teorías del caos y la autoorganización, en las que la realidad es concebida como actividad, proceso, relaciones, sistemas - físicos, biológicos y socioculturales- en constantes estructuración y con similares pautas de autoorganización.

La autoorganización implica, en el plano horizontal, la combinación y asociación de las partes en un todo siempre cambiante. En el plano vertical la evolución por saltos discontinuos y explosivos con profunda transformación de estructuras que se integran en formas cada vez más complejas.

\section{El pensar y el sentir}

Ya podemos aproximarnos al tema propuesto y a la comprensión de que cada parte del cuerpo, cada reacción química, muscular y nerviosa, interacciona con todas las demás y depende de todas las demás. La vida misma es un sistema complejo de interacciones dialécticas, capaz de crear y mantener por sí sola el fenómeno que conocemos con el nombre de vida. En el fluir incesante de las operaciones mentales en interacción comunicativa con el medio, coexisten el pensamiento y el sentimiento como componentes interactivos de la experiencia humana.

Es un pensamiento extraño y sorprendente, que de esta manera, cada uno de nosotros estemos involucrados en un proceso de movimiento y de intercambio rítmico de partículas los unos con los otros, y con la tierra, los animales, el sol, la luna, las estrellas, hasta la galaxia más remota y actualmente con la tecnología.

El mundo social es un mundo vivo, pasional, en el que cada uno va tallando su identidad en virtud de su exigencia de ser parte de algo, ser amado y amante, para poder sostener sus placeres y ser confortado en sus dolores; ese poder suave de la imaginación es tan natural como generoso y benevolente, pues arma la imagen de nosotros, de comunidad y así posibilita el punto de vista imparcial e intersubjetivo; de él surgen los sentimientos compartidos. 
El sentir nos lleva al mundo fenoménico de aquello que es pre-racional. Una aproximación interesante al sentir nos la entrega la psicoterapia experiencial (Gendlin, 1978), en la que se utiliza el concepto de sensación-sentida, para referirse a aquella corriente de sensaciones que se encuentra a la base de nuestra experiencia, es al focalizar nuestra atención en este fluir que emergen los significados que atribuimos a la experiencia en nuestra conciencia. Generalmente una sensaciónsentida no está completa en nuestro cuerpo, sino que tiene que formarse. Es necesario saber cómo dejarla configurar, atendiendo a nuestro interior. La sensación-sentida no es una experiencia mental sino física, que luego es simbolizada por medio de palabras, gestos, sonidos e imágenes. Es la reacción holística de todo nuestro organismo ante algo que está sucediendo en nuestra vida. No es una emoción, pero puede contenerla (Gendlin, 1978). Los seres humanos integramos las percepciones provenientes de nuestros sentidos en aquella complejidad pre-cognitiva que es también conocida como el inconsciente por las teorías psicoanalíticas.

Tanto en el ámbito de la conciencia como en el aprendizaje humano, es fundamental la interacción de los fenómenos biológicos con los de carácter simbólico y estos a su vez con el medio ambiente, que constituyen entre sí sistemas de interacción que permiten que emerjan diferentes órdenes de organización de los sistemas complejos.

En esta línea es muy aclaratorio el pensamiento de Edgar Morin (1980), quien concibe al ser humano como ser bio-cultural porque es producto de un proceso evolutivo de hominización. Un proceso morfogenético, generativo, relacional en el que intervienen de forma recursiva los niveles biológico / cerebral / individual / social / cultural / ecológico. La evolución biológica del hombre que desemboca en la constitución del gran cerebro sapiencial es impensable si no comprendemos que la cultura ha sido fundamental en ese proceso. Más aún, un cerebro sin la información cultural no sería nada ni serviría para nada, solo sería un órgano biológico. El cerebro humano debe ser considerado como un sistema bio-cultural. Un sistema en el que la autoorganización biológica es posible gracias a que la información cultural producida por las interacciones sociales entre los individuos actúa como estímulo que hace que ese cerebro complejice sus interrelaciones internas. Y al mismo tiempo hay que entender que la sociedad homínida se va complejizando cada vez más debido a que el cerebro adquiere cada vez mayores capacidades. Complejidad socio-cultural y complejidad bio-cerebral van a la par. No hay lugar a dudas, el cerebro es también un órgano social (Morin, 1980).

Y en esta complejidad el ámbito del sentir se hace presente en todo el proceso. Las emociones, los afectos, los sentimientos, son formas de nominar estados internos y manifestaciones externas de las relaciones entre personas. A través de estas relaciones, cargadas de emoción, se desarrollan los procesos básicos en la construcción de la individualidad humana: la imitación y la identificación con otros individuos y grupos.

Es importante destacar que la emoción es el principal favorecedor del encuentro con el otro. Etimológicamente significa moverse hacia fuera, salir de uno. La respuesta intensa, ya sea de aproximación o de evitación, es la forma visible de la experiencia emocional. Estas respuestas se producen por rápidas y profundas transformaciones fisiológicas juntas con las apreciaciones valorativas que hace el individuo del contexto de significación, es decir, del sentido de lo que ha producido la emoción, por ejemplo la aceleración del ritmo cardiaco en presencia del enamorado.

En el mundo mamífero y sobre todo en el mundo humano, el desarrollo de la inteligencia es inseparable del de la afectividad, es decir, de la curiosidad, de la pasión, que son a su vez, fruto de la capacidad de investigación filosófica o científica. Existe una estrecha relación entre la inteligencia y la afectividad: la facultad de racionamiento puede verse disminuida y hasta destruida por un déficit de emoción; un debilitamiento de la capacidad para reaccionar emocionalmente puede llegar a ser la causa de comportamientos irracionales.

Veamos nuestro sistema cognitivo. Ningún dispositivo cerebral permite distinguir la alucinación de la percepción, el sueño de la vigilia, lo imaginario de lo real, lo subjetivo de lo objetivo. Dado que las vías de entrada y de salida del sistema neurocerebral que conectan el organismo con el mundo exterior representan sólo el $2 \%$ de todo el conjunto, mientras que el $98 \%$ implica el funcionamiento 
interior, se ha constituido en un mundo psíquico relativamente independiente donde fermentan necesidades, sueños, deseos, ideas, imágenes, fantasmas, y todo este mundo se infiltra en nuestra visión o concepción del mundo exterior (Morin, 1980).

Lo que permite la distinción entre sueño y vigilia, imaginario y real, subjetivo y objetivo, es la actividad racional de la mente que apela al control del entorno (resistencia física del medio al deseo y al imaginario), al control de la práctica (actividad verificadora), al control de la cultura ( referencia al saber común), al control del prójimo (¿usted ve lo mismo que estoy viendo yo?), al control cerebral (memoria y operaciones lógicas). Dicho de otra manera, la racionalidad es la que corrige.

A medida que el niño crece la educación de los sentimientos es parte del conjunto de pautas de comportamiento, valores y expectativas acerca del otro y acerca de uno mismo que se le transmiten en la socialización. De esta manera hay sentimientos que se deben experimentar en determinada situación y no en otras, y con determinadas personas y no con otras. De ahí que el control de las emociones sea una de las características de la especificidad cultural. Este hecho es muy importante al considerar que el amplio margen de acción de los medios audiovisuales hace que millones de seres humanos, que viven a miles de kilómetros de distancia y de culturas distintas, compartan opiniones y gustos similares sobre cine, moda, comida y aspiren a conseguir las mismas metas vitales, todo ello por efecto unificador de la comunicación a través de las pantallas.

Pues bien, en nuestro mundo actual globalizado, los medios masivos de comunicación están estimulando las conciencias de seres humanos de diversas procedencias y orígenes culturales. Y podemos entender la conciencia como la actividad mental interpuesta entre la estimulación y la acción. Comprende fenómenos como síntesis, análisis, deliberación, interpretación, planificación y los sentimientos (Torres, 2002). El alcance y responsabilidad frente a esta situación nos sitúa frente a una reflexión ética fundamental sobre las formas de pensamiento que diariamente se fomentan por los medios.

¿Qué esta pasando entonces con las nuevas tecnologías? La tecnología clásica, por definición, especializa, lleva a un enriquecimiento en lo secuencial, lo previsible, estructurado, es desmedro de lo totalizador, abierto, incierto e inspirado. Los nuevos tipos de tecnología han producido nuevos tipos de relaciones humanas, nuevos significados y por lo tanto nuevos tipos de seres humanos, con nuevas formas de expresión. El desarrollo creativo de la mente implica una modulación, una integración, entre el hemisferio izquierdo, lógico lineal, secuencial, con el derecho, analógico, metafórico y poético.

Por su parte, consideremos algo bien sabido por la publicidad, para que un producto comunicativo cumpla su objetivo debe llamar nuestra atención y ser significativo para nosotros, debe seducirnos. La seducción parte del intelecto y se dirige a las emociones; su valor es connotativo. Seduce lo natural, lo que se liga al ser humano y su entorno, a sus costumbres, a las historias, olores, sonidos y visiones. La seducción reside en los afectos, no en las razones. Ante determinadas palabras los mecanismos internos del ser humano se ponen en marcha con estímulos físicos que desatan el sentimiento de aprecio o rechazo, no repara en abstracciones sino en lo concreto, lo singular frente a lo general. Las posibilidades de tecnologías que incorporen otras modalidades sensoriales como el olfato, el tacto o el gusto nos abre caminos insospechados para seducir nuestra conciencia y llevar al ser humano a nuevas modalidades de aprendizaje.

Pero todo esto nos debe llevar a reflexionar sobre otros aspectos, en el ámbito de la mediación los seres humanos nos hallamos inmersos ante una oferta comunicativa cada vez más diversa y tecnológicamente más perfeccionada hacia el establecimiento de entornos virtuales que asemejen a la realidad. Es importante estar alerta sobre quiénes están detrás de estos productos y a qué grados de manipulación se encuentran expuestos los usuarios de estas tecnologías. Son un hecho los desarrollos tecnológicos pero ¿serán beneficiosos para todos los seres humanos o sólo para algunos?

La interacción entre el ser humano y las nuevas tecnologías puede tener variadas consecuencias, por un lado puede fomentar el desarrollo de competencias cognitivas sorprendentes, pero también 
se corre el riesgo de la alienación y el sometimiento a mundos alternos que pueden llevar a la emergencia de trastornos psicológicos de adaptación social o, más aun a estados psicóticos con pérdida del sentido de realidad. Claro que para llegar a estos extremos entran en juego otros factores y su incidencia requeriría de estudios y análisis mucho más allá de los alcances de esta exposición, pero considero importante plantearlo como una trayectoria posible a tener en cuenta en la reflexión sobre estos temas.

Volvamos ahora a nuestro tema de la dialéctica entre el pensar y el sentir, pero ahora en relación con las nuevas tecnologías. La búsqueda de una realidad simulada ha llegado a su extrema consecuencia en la realidad virtual. Nuestros sentidos, más que ser engañados, son, lisa y llanamente, reemplazados y absorbidos por el sistema electrónico.

Este viaje en la cibercultura nos permite descubrir que hay esferas de la realidad inaccesibles al método de la medida y del experimento, las relaciones entre la percepción y los entornos virtuales amplifican las posibilidades de la conciencia.

Y si de la conciencia y sus atributos se trata, tenemos innumerables ejemplos de tradiciones ancestrales que a través de prácticas chamánicas constataron que algunas realidades sólo se alcanzan por la intuición y en forma enigmática. Los viajes chamánicos y los estados alterados de expansión de conciencia inducidos por sustancias o ejercicios respiratorios tienen muchos componentes de virtualidad. Permiten que nuestra conciencia interactúe con simbolismos y experiencias corporales de un orden de percepción diferente al razonamiento lógico que permite establecer un "sentido de realidad”.

El experimentar otras realidades se ve favorecido con el avance tecnológico, lo que ha producido paradójicamente la explosión de los sentidos. Máquina y seres humanos parecen fundirse en un nuevo sistema, caracterizado por una sorprendente y novedosa interactividad. Los mundos-redes electrónicos y la cibercultura en general, representan la posibilidad de una poderosa rearticulación entre humanos, animales y máquinas.

La revolución cibernética se caracteriza por productos comunicacionales que evolucionan desde los rígidos formatos del texto escrito hasta llegar a convertirse en software adaptables interactivos y en tiempo real. La información se vuelve más accesible, los usuarios toman y eligen lo que desean, y cada uno de ellos es un creador de contenido. Los comunicadores cambian su tradicional postura de líderes autosuficientes para convertirse en guías.

Al conocimiento inductivo-deductivo se va sumando el conocimiento por simulación. Vuelve el concepto de aprendizaje práctico, a ritmo personal. El Juego intelectual que nos permite entrar en el mundo de la programación de computadoras aplica estas nuevas formas de aprender. Jugando, simulando, haciendo cosas concretas con un computador uno va aprendiendo; al trabajar con un programa, se aprende sobre la estructura de los datos y otros elementos del software.

El hipertexto constituye un soporte de memoria que se diferencia radicalmente de la escritura lineal, en el sentido en que constituye un entorno de experiencia en el que diferentes procesos de cómputo pueden ser exteriorizados, simulando de esta manera, la capacidad del cerebro para almacenar y recibir información.

Las ventanas pueden obligar a la mente a configurarse como una estructura hipertextual, manipulando varias operaciones al mismo tiempo. Una vez que nos hemos familiarizado con este proceso, podemos codificar y descodificar nuestro entorno habitual con las herramientas que hemos aprendido a utilizar con los medios de soporte.

El principio de la hipertextualidad le permite a uno tratar la Red como la extensión de los contenidos de su propia mente, incluyendo los afectos.

El texto desde sus más remotos orígenes ha sido una forma externa de memoria, así como un mecanismo mediante el cual son exteriorizados diferentes modelos de organización de pensamientos y reflexiones. 
Desde esta perspectiva, el efecto de la tecnología en nuestros sistemas de comprensión puede pensarse como una continuación de esta constitutiva plasticidad de la cognición humana, en la que los instrumentos textuales contribuyen en la modificación de las competencias mentales de representación, así como en las estructuras de asociación y producción simbólica.

El hipertexto no es sólo un nuevo sustrato o dispositivo mediante el cual podemos comunicarnos, es un concepto que puede ser empleado para describir concepciones, métodos, sistemas y herramientas. En tanto una estructura o modelo exterior de representación, el hipertexto ha de pensarse como mapa de navegación por el que son posibles diversos recorridos de significación, quizá también recorridos de múltiples niveles de conceptualización y experimentación.

El hipertexto es ante todo un instrumento que debe llevarnos a pensar en la construcción de nuevas habilidades de acceso, nuevos lectores que a su vez se conviertan en autores de nuevos recorridos, en nuevos usuarios de esa reserva global de conocimiento en la que tendremos que guiarnos desarrollando asociaciones pertinentes y nuevos recorridos significativos.

\section{Cibercultura}

Una de las líneas de pensamiento que considero un aporte para esta, es la emergencia de lo que se ha llamado cibercultura, basándome principalmente en los planteamientos del profesor Luis Jesús Galindo Cáceres, quien ha trabajado estos temas desde las ciencias cognitivas y de la comunicación. En sus trabajos realiza una descripción de las formas de entender a la sociedad a partir del uso de los medios de comunicación. Plantea un desarrollo secuencial que pasa por las metáforas de la sociedad texto, la sociedad gramatical y la cibersociedad (Galindo, 2001a).

Describe a la sociedad texto como una configuración fija de representaciones sobre el mundo, de las relaciones entre los seres vivos parlantes y creadores de posibilidades. El libro es la mejor metáfora de la sociedad texto. Siempre el mismo, idéntico a sí mismo día a día, año tras año, permanente mientras no se desintegre. Pero con una condición, el libro eterno requiere una lectura eterna. Es decir, tanto texto como lectura deben ser estables y fijas por siempre, que la mente tome la imagen del cristal, siempre limpio y puro, inmóvil y confiable. "La sociedad fue construida, levantada sobre la metáfora de la inmovilidad. Lo que estaba en las escrituras era lo real y sagrado. Y la energía fue invertida en que así fuera y esa sociedad pareció perpetuarse en el tiempo, anularlo por completo, vencerlo. Pero no, el mundo cambió y lo eterno humano se desmoronó y desapareció, o casi" (Galindo, 2001a, p. 1).

Otra sociedad apareció; la imprenta y la alfabetización masiva contribuyeron en esto; el texto permaneció como figura que obliga, que ordena, que organiza, pero la lectura se liberó. Otro mundo emergió de las posibilidades de interpretar, de significar. El control sobre la mente se mantuvo gracias a la textualidad como imagen de la disciplina que permite avanzar. En principio cualquiera que tuviera acceso a las normas de construcción podría leer lo armado a partir de ellas, y podría escribir. Pero muchos tuvieron la oportunidad de leer, pero pocos tuvieron la oportunidad de escribir y de ser leídos. El control sobre el texto garantizó aún cierto control, más sutil, con menos gasto energético, con mayores posibilidades de manejo de la apariencia de la nueva libertad gramatológica.

La metáfora de la gramática abrió al espacio social, diversificó a la población. El número de textos se multiplicó y el de lectores también. Aquella sociedad de pocos textos, pocos escritores y pocos lectores pronto cambió su configuración. Y hubo más lectores, escritores potenciales, pero no escribían, y si escribían no tenían opciones de ser leídos. El control sobre la difusión de los textos, así como sobre su producción material, permitió que el antiguo paradigma se continuara aun con una ecología gramatical emergente. La sociedad gramatical proponía la libertad de lectura y de escritura, pero sólo permitía la primera, y bajo ciertos condicionamientos de aparatos políticos, ideológicos y económicos (Galindo, 2001a).

Entonces tuvo que llegar la cibersociedad para abrir el espacio a la escritura y con ello cumplir el ciclo de lo cerrado a lo abierto de la textualidad. El hipertexto permitió por primera vez la 
posibilidad de construcción de la textualidad desde la lectura. En el hipertexto, el texto mismo se modifica en la lectura. La multiinteractividad permite la configuración de la textualidad construida en tiempo real desde distintos lugares y puntos de vista. La revolución de la cibersociedad trajo nuevos cursos metafóricos; ahora es posible leer y escribir, y hacerlo en grupo y colectivamente, no sólo la interactividad sino la multinteractividad, no sólo la escritura sino la hipertextualidad. El ciberespacio social inaugura la metáfora de la configuración de mundos distintos desde la interacción real en el espacio virtual.

Entonces, con la apertura del ciberespacio emerge una nueva forma de socialización, mediado por el ciberespacio se presentan capacidades de relaciones horizontales. Internet funciona como una metáfora vital de las posibilidades del contacto múltiple horizontal, permite la multiinteractividad y con esto una nueva forma de construcción de vida social a través de nuevas formas de contacto, de relación y de vínculos.

Galindo plantea que la cibercultura presenta una doble configuración en su exploración conceptual. Por una parte está la banda de la cibernética y de la teoría de sistemas. Ésta es una veta ecológica que toca a la cultura con la vivencia del pensamiento complejo contemporáneo y supone una construcción de la vida a través de categorías y de visiones emergentes. El segundo frente parte de lo empírico, del reconocimiento de nuevas realidades que impulsan a nuevos conceptos y percepciones, este es el marco de las nuevas tecnologías, en particular las relacionadas con la información, y en especial las que son calificadas como inteligentes, desde una mirada compleja del mundo digital (Galindo, 2001a).

En la primera visión quizás lo más sugerente es la perspectiva de la virtualidad abierta al mundo real anterior. En el marco conceptual de lo virtual, los mundos son sintetizados a partir de ciertos modelos de construcción simbólica. Esto es clave para la noción de cibercultura. En el pasado reciente se consideraban mundos reales a los que los actores vivían desde sus miradas y desde sus situaciones de vida. Ahora esos mundos también forman parte de la virtualidad en tanto son sintetizados desde algún esquema de construcción perceptual.

El asunto es que la cultura pasa entonces del mundo sintetizado al modelo que lo sintetiza, es decir, aquello de la metáfora de la gramática y del texto. La cultura era texto en cierta mirada, lo que aparecía, lo que acontecía. El discurso cultural era una serie de catálogos de la fenomenología de lo social. En la segunda metáfora, la gramática ocupa el lugar central. Ahora es el modelo de síntesis virtual el importante, no lo que aparece. Pero falta lo mejor. La virtualidad es una actividad constructiva, no representacional o contemplativa. Es decir, el énfasis está puesto no en el mundo vivido o que se vive, lo que había sido el objeto de la mirada cultural en el pasado, sino el mundo por vivir, por construir, el futuro. La importancia del modelo lleva la mirada y la intención a la construcción de mundos posibles a partir de los modelos que los pueden sintetizar. Y el mensaje es: tú puedes vivir en los mundos que puedes crear a partir de los recursos disponibles para reconfigurar tu percepción de la vida.

Esta dimensión de la cibercultura la hace muy distinta a la cultura tradicional, moderna o no. El mundo puede cambiar, y además el énfasis está en su transformación. El pasado, el texto, la identidad, la inmovilidad, quedan detrás; lo que importa es lo que se puede hacer, la acción, no la imagen de lo que es, que inmoviliza, o la representación de lo que puede ser, que la posterga. El mundo cibercultural es el que se está construyendo ahora, el que se teje en este momento. Y la mirada social, cultural, no está en lo que aparece, el mundo virtual, sino en lo que lo hace aparecer, sintetizador de la virtualidad. En el ciberespacio es más sencillo por ahora imaginar la práctica de la creación constante y acelerada. Pero la metáfora va más allá, impacta al seudo mundo real y nos invita a modificarlo, a transformarlo. Entendida de esta manera la cibercultura es revolucionaria.

Queda entonces la segunda veta, la que llega de la reflexión sobre las nuevas tecnologías, en particular la interacción con máquinas inteligentes. Este es un universo de posibilidades. Hay un énfasis muy grande en la competencia cibercultural cuando se observa la empatía y práctica de interacción con máquinas de información, computadoras en particular. Y el fenómeno se hace 
incluso más complejo cuando esta relación opera en una red de interacciones entre seres humanos y máquinas, donde la red los implica a ambos, constituyendo una nueva configuración mixta, humana y de máquinas.

En este rango, el miedo a la deshumanización se hace presente, y cuando se observa a las máquinas construidas por la lógica de información, del control, de la dominación, y se percibe su limpieza, su exactitud, su poder de manejo de datos, su precisión, entonces el pavor aparece. Es como un monstruo hecho a la imagen y semejanza del tirano, del dictador, de la lógica vertical. Entonces la paranoia aparece, se reproduce la misma lógica de la dominación, la máquina o quienes están tras ella pueden dominarme, por tanto debo destruirla o someterla antes que lo haga ella conmigo. Pero resulta que ese escenario no es el único. La lógica de comunicación, de la vida horizontal, de diálogo, de la interacción, del enriquecimiento mutuo también está presente, y gana espacio gracias a la red de relaciones, no gracias a la concentración de información en un solo lugar. La red es la respuesta a la paranoia de la sociedad de información; entre más grande, entre más múltiple y diversa, menos posibilidades de control central autárquico. Aparece una nueva sociedad con una nueva cultura, la cibersociedad y la cibercultura.

La pregunta hoy, en este nuevo territorio de lo social, es sobre los tipos nuevos de relación, sobre los cambios en las rutinas y patrones de la vida cotidiana previos. Por un lado, los que descubren la decadencia del calor humano ante la frialdad de las interacciones mediadas por máquinas. Por otra parte, los que proponen que se inaugura un mundo de posibilidades, y que la sociedad no sólo no se corrompe, sino que mejora, se tensa en un nuevo escenario de vínculos con mayor competencia comunicacional y honestidad.

Lo que sigue es el juego constructivo del nuevo espacio conceptual. Elementos como comunicación, interactividad, hipertextualidad, conectividad, redes, virtualidad, aparecen en escena. Son muchos los que van explorando sus contenidos y sus aplicaciones. Lo interesante es la dimensión reflexiva; la cibercultura supone más intersubjetividad, más diálogo y conversación entre distintos y semejantes. Este frente se va armando desde distintas regiones, en diversos lugares, todo ello con la apuesta de la formación de una ecología social más interconectada, más reflexiva, más dialógica y dialéctica. La nueva visión de la totalidad está en marcha, supone la participación de todos por todos los medios posibles.

La cibercultura puede ser el punto de apoyo para ir vislumbrando el futuro de entre las visiones que insisten en percibir una visión anacrónica, que ya no está a la altura de los tiempos que corren. No será tarea fácil, el mundo y sus cambios continúa sus cursos de posibilidad dependiendo de diversas fuerzas de construcción y creación de lo social, el metabolismo de su movimiento es muy acelerado, es urgente que los cambios conceptuales vayan emparejando el paso. Si internet cambiará la vida de los habitantes de este planeta con figuras evolucionadas por ahora inimaginables, tal y como sucede en este momento, su comprensión puede participar en la acción. No sabemos lo que sucederá, sabemos que podemos participar de diferentes formas, una de ellas puede ser la que apuesta por la percepción-reflexiva-constructiva-interactiva, la de una cibercultura que permita que todos jueguen, o por lo menos los más posibles.

\section{Usos Comunicativos de las nuevas capacidades tecnológicas}

Los usos de las nuevas tecnologías son variados: Influencias en las formas de ocio de los niños y jóvenes; la creación de materiales didácticos pedagógicamente innovadores; la aplicación de los principios de la IA (Inteligencia Artificial) al software educativo; la utilización de Internet en el aula desde posiciones constructivistas y psicopedagógicas; la educación a distancia o eLearning; las desigualdades en el acceso a la tecnología y las políticas de alfabetización en la cultura digital; aplicaciones en el campo de la salud como telemedicina o psicoterapia; intercambios comerciales, etc. 
Me centraré en su presencia consolidada en el campo de la educación. Fundamentalmente, porque la industria ha visto claro que el futuro está en habituar a los nuevos usuarios en estas tecnologías desde edades tempranas. Y esto se viene propiciando tanto en el ámbito escolar como en el familiar. Además, la investigación educativa viene profundizando en la incidencia que herramientas como los multimedia pueden tener en los procesos de aprendizaje.

Uno de los campos en el que la aplicación de las nuevas herramientas multimedia ha avanzado más, es conocido por el edutainment. Que es una contracción de las palabras education y entertainment, que identifican aquellas propuestas con soporte informático que combinan educación y entretenimiento. Una de las facetas que en este ámbito ha tenido más desarrollo es el de los videojuegos o aventuras virtuales. La realidad virtual como concepto incluye tres aspectos básicos: la inmersión; la interacción y la navegación. La inmersión puede ser entendida como inclusión física en la imagen mediante hardware como cascos estereoscópicos o láser retiniano. La interacción supone asumir el punto de vista de un personaje que interactúa con otros en ámbitos aparentemente reales. Y la navegación consiste en recorrer los espacios virtuales. Navegar es orientarse en los laberintos de información que están en continua evolución (García García, 1998; en De Pablos). El potencial intrínsecamente educativo de estos materiales radica en su capacidad para propiciar una lectura o acceso no lineal de los documentos, favoreciendo por tanto distintas construcciones de la realidad. Los alumnos deben ser formados para ser capaces de comprender e integrar en su oralidad audiovisual los códigos de imagen y sonido, presentes en estos materiales. La creación de productos multimedia basados en modelos comunicativos y teorías del aprendizaje que apoyen estrategias educativas innovadoras, constituye un reto en la actualidad.

Los usos educativos en la actualidad responden a diferentes planteamientos. Cubren desde las áreas curriculares específicas, hasta propuestas basadas en el uso de destrezas cognitivas y motoras (razonamiento lógico, resolución de problemas, visomotricidad, etc.), pasando por herramientas de consulta (enciclopedias, atlas, museos virtuales, etc.).

Y en este entorno es importante considerar que las generaciones más jóvenes, es decir, los nacidos a lo largo de la década de los noventa, han sido socializados culturalmente bajo la influencia de las nuevas tecnologías de la información y comunicación en sus diversas variantes (televisión digital, telefonía móvil, Internet, videojuegos); éstos presentan una serie de rasgos de comportamiento social y cultural diferenciados respecto a los niños y adolescentes de décadas anteriores. Lo cual, en consecuencia, requiere que los padres y docentes se planteen nuevos modelos educativos y métodos de enseñanza.

El alumnado actual es una generación que ha sido socializada culturalmente en contacto permanente con variadas tecnologías audiovisuales e informáticas. Para estos niños y adolescentes es algo cotidiano acceder a múltiples canales de televisión y zapear de unos a otros, escribir sus trabajos de clase en un ordenador, llamar y recibir mensajes a través de telefonía móvil, navegar por Internet en busca de información, y comunicarse con sus amigos a través de un chat. Dicho de otro modo, los alumnos son usuarios de numerosas y diversas tecnologías siendo éstas un elemento familiar de su vida, y hasta cierto punto, indispensables.

Pero también, a diferencia de generaciones precedentes, los estudiantes de hoy en día, al igual que el resto de ciudadanos, están expuestos a un continuo flujo de información que provoca saturación de datos. La televisión, Internet, el cine, la publicidad, la radio, etc., permanentemente están difundiendo acontecimientos, noticias, opiniones, ideas que llegan como una avalancha interminable. En consecuencia, la cantidad de información que los alumnos poseen sobre los acontecimientos de la realidad -sea de tipo político, deportivo, musical, o de sucesos- es abrumadora. Pero mucha información, no significa necesariamente más conocimiento.

El problema educativo que se deriva de este hecho consiste en cómo ayudar al alumnado a dar sentido y forma a todo ese cúmulo de información que éstos obtienen desde que se levantan hasta que se acuestan. El nuevo reto para la sociedad es ayudar a reconstruir dicha información con la finalidad de convertirla en un conocimiento comprensible y con significado. Esta meta 
educativa requiere que se potencien y se desarrollen en los alumnos las habilidades y competencias relacionadas con la búsqueda de información, con saber discriminar lo que es información útil y de interés para ciertos propósitos, analizar y contrastar datos obtenidos de diversas fuentes, aprender a organizarla, reconstruirla y difundirla. En definitiva, es enseñar a utilizar la enorme información disponible y las posibilidades de comunicación ofertada por las TIC de forma inteligente y crítica.

A modo de conclusión, quisiera destacar que sin lugar a dudas las nuevas tecnologías de la información y la comunicación son nuestro presente y nuestro futuro, son un espacio abierto de conocimiento y reflexión de amplio alcance. Y el uso comunicativo está abierto a las posibilidades tanto para la comunicación horizontal, dialógica, tendiente al desarrollo, como también para incentivar la difusión de procesos verticales de transmisión de información más relacionados con el ámbito de la dominación que con la comunicación para el desarrollo. Es en las prácticas sociales y sus regulaciones políticas, económicas y culturales en las que se sostienen los usos comunicativos de las nuevas capacidades tecnológicas. Y así, se construyen los mundos posibles, por un lado la expansión de conciencia, la interconectividad y el cambio social, y tal vez, por el otro, formas sofisticadas de dominación, alienación y dependencia. La intención es que cada cultura, en el marco de la sociedad global, pueda desarrollar sus propios significados, desarrollar sus propios usos y gratificaciones y usar las nuevas tecnologías de diversas maneras. La dialéctica entre el pensar y el sentir se ha constituido en una unidad compleja con las nuevas capacidades tecnológicas, y las trayectorias posibles son el punto de partida para el debate. Los invito entonces a comunicarnos y construir el mundo que soñamos.

\section{Referencias}

De Pablos, J. (N.D). "Las tecnologías de la información y la comunicación: un punto de vista educativo”. Extraído el 21 de julio de 2006 desde http://www.ucm.es/info/multidoc/multidoc/ revista/num8/jpablos.html

Galindo Cáceres, J. (2001a). Cibercultura, Ciberciudad, Cibersociedad. Hacia la construcción de mundos posibles en nuevas metáforas conceptuales. Extraído el 21 de julio de 2006 desde http:// www.geocities.com/arewara/arewara.htm

Galindo Cáceres, J. (2001b). Internet y Cibercultura. Nueva cultura y formas emergentes de sentido. Extraído el 25 de julio de 2006 desde http://www.geocities.com/arewara/arewara.htm

Gamba, A. (2004). Hipertexto y pensamiento: una búsqueda de nuevas herramientas de interlocución. Extraído el 21 de julio de 2006 desde http://www.ub.es/prometheus21/articulos/obsciberprome/ Gamba.pdf

Gendlin, E.T. (1978). Focusing. New York: Everest House.

Goñi, P., Lee, Franz J.T. La Dialéctica, el Método Dialéctico y el Pensamiento Dialéctico. Extraído el 18 de julio de 2006 desde http://www.franz-lee.org/files/pandemonium00911.html

Morin, E. (2001). Los siete saberes necesarios para la educación del futuro. Barcelona: Ediciones Paidós Ibérica S.A.

Piscitelli, A. (1995). Enredados...tele-ciudadanos de la cibercultura. En E. Dabas y D. Najmanovich (Eds.). Red de Redes. Buenos Aires: Ed. Paidós.

Sobrino Blanco, M. (1992). "Problemas teóricos y metodológicos que se plantean en la investigación de alguno de los nuevos productos informacionales de uso comunicativo”. En La Investigación en la Comunicación. III Simposio de la Asociación de Investigadores en Comunicación del Estado Español. Madrid.

Torres, E., Conde, E., Ruiz, C. (2002). Desarrollo Humano en la Sociedad Audiovisual. Madrid: Editorial Alianza. 